\title{
Effects of agricultural biodiversity and seasonal rain on dietary adequacy and household food security in rural areas of Kenya
}

Florence K M'Kaibi ${ }^{1}$, Nelia P Steyn ${ }^{2,5^{*}}$, Sophie Ochola ${ }^{3}$ and Lisanne Du Plessis ${ }^{4}$

\begin{abstract}
Background: Kenya has a high prevalence of underweight and stunting in children. It is believed that both agricultural biodiversity and seasonal rainfall influences household food security and dietary intake. In the present study we aimed to study the effects of agricultural biodiversity and seasonal rains on dietary adequacy and household food security of preschool Kenyan children, and to identify significant relationships between these variables.

Methods: Two cross-sectional studies were undertaken in resource-poor households in rural Kenya approximately 6 months apart. Interviews were done with mothers/caregivers to collect data from randomly selected households $(\mathrm{N}=525)$. A repeated 24-hour recall was used to calculate dietary intake in each phase while household food security was measured using the Household Food Insecurity Access Scale (HFIAS). A nutrient adequacy ratio (NAR) was calculated for each nutrient as the percent of the nutrient meeting the recommended nutrient intake (RNI) for that nutrient. A mean adequacy ratio (MAR) was calculated as the mean of the NARs. Agricultural biodiversity was calculated for each household by counting the number of different crops and animals eaten either from domestic sources or from the wild.
\end{abstract}

Results: Dietary intake was low with the majority of households not meeting the RNIs for many nutrients. However intake of energy $(p<0.001)$, protein $(p<0.01)$, iron $(p<0.01)$, zinc $(p<0.05)$, calcium $(p<0.05)$, and folate $(p<0.01)$ improved significantly from the dry to the rainy season. Household food security also increased significantly $(p<0.001)$ from the dry (13.1 SD 6.91) to the rainy season (10.9 SD 7.42). Agricultural biodiversity was low with a total of 26 items; 23 domesticated and 3 from the natural habitat. Agricultural biodiversity was positively and significantly related to all NARs (Spearman, $p<0.05$ ) and MAR (Spearman, $p<0.001$ ) indicating a significant positive relationship between agricultural biodiversity of the household with dietary adequacy of the child's diet.

Conclusion: Important significant relationships were found in this study: between agricultural biodiversity and dietary adequacy; between agricultural biodiversity and household food security and between dietary adequacy and household food security. Furthermore, the effect of seasonality on household food security and nutrient intake was illustrated.

Keywords: Dietary intake, Dietary adequacy, Biodiversity, Household food security, Kenya

\footnotetext{
* Correspondence: nelia.steyn@uct.ac.za

${ }^{2}$ Division of Human Nutrition, Department of Human Biology, University of Cape Town, Anzio Road, Cape Town, South Africa

${ }^{5}$ Division of Human Nutrition, Department of Human Biology, Faculty of Health Sciences, UCT Medical campus, Anzio Road, Anatomy Building, Floor 2, Room 2.04, Observatory 7925 Cape Town, South Africa

Full list of author information is available at the end of the article
} 


\section{Background}

Kenya is classified by the Food and Agricultural Organization (FAO) as a low-income-food deficit country [1]. It is among the one third of African countries whose food availability shows an average daily caloric availability below the recommended level of 2100 Kilocalories [2]. A recent economic review indicated that $51 \%$ of the population lack access to adequate food [3]. This inaccessibility to food is closely linked to poverty which stands at $46 \%$ [4]. The country has been facing serious food insecurity due to reduced cereal production, livestock diseases, rising food prices and poor rainfall. The food shortage situation was declared a national disaster at the beginning of January 2009 and May 2011 indicating that about 10 million persons were highly food insecure [5,6]. The most recent Democratic and Health Survey findings on child nutritional status showed that $16.1 \%$ of children aged below 5 years were underweight and $35.3 \%$ were stunted [7], indicative of poor household food security in a large proportion of the population.

Agricultural biodiversity helps to promote development and improves household food security [8]. There has, however, been a decrease in agricultural biodiversity in many developing countries, which has led to a reduction in the variety of animals reared for food and plants grown by households or picked in the wild [9]. This has led to a simplification and decrease in diversity of diets of a large number of people to a limited number of energy food sources that may not confer specific micronutrients, essential amino acids and essential fatty acids [10]. There is limited evidence of studies in sub-Saharan Africa linking agricultural biodiversity with household food security and nutritional status. In order to improve nutritional status it is therefore crucial to study the role of biodiversity as a factor which impacts on household food security [11].

In households with poor food security, low quality, monotonous diets are the norm. These diets generally constitute a large proportion of starchy foods which include cereals and tubers and are low in vegetables, fruits and animal protein $[12,13]$. The diets tend to be low in a number of micronutrients, and the micronutrients they contain are often not bio-available, thus resulting in deficiencies [13]. The risk of such deficiencies is high, particularly in children under the age of five years.

Undernutrition, including micronutrient deficiencies in early childhood may lead to a number of cognitive and physical deficits and may cause similar deficits in future generations as malnourished girls, particularly those with stunted growth, who become mothers, are at increased risk of giving birth to low birth weight infants [14]. The effects of undernutrition on human performance, health and survival have been the subject of extensive research for several decades [15]. Studies show that undernutrition affects physical growth, morbidity, mortality, cognitive development, reproduction, and physical work capacity [15]. Evidence from research carried out in developed countries show that dietary diversity is strongly associated with nutrient adequacy. A number of researchers from developing countries have also shown this association [16-21].

A study in Kenya by Ekesa et al. [22], showed a strong relationship between agricultural biodiversity and dietary diversity. The findings showed that almost $50 \%$ of changes in dietary intake of preschool children were due to changes in agricultural biodiversity. This implies that improving biodiversity can improve dietary diversity, which in turn can lead to an improvement in nutritional status [22]. In the present study we aimed to study the effects of agricultural biodiversity on dietary adequacy and household food security of preschool Kenyan children 24-59 months old, and to identify significant relationships between these variables.

\section{Methods \\ Sample}

Based on an effect size of 0.4 with $90 \%$ power and a significance level of $5 \%$, a sample of 500 respondents (250 in each area) was required. The latter was based on the current national statistics for stunting (35\%) in under-five children. The areas studied were resourcepoor households in two rural districts of Meru in Eastern Province, Kenya namely: Akithii and Uringu. Uringu has a better rainfall and geographic resources compared to Akithii however in other respects the districts are similar being about $25 \mathrm{~km}$ apart. The households were randomly sampled by means of table of random numbers. A slight oversampling was done resulting in a total of 261 participants from Uringu division and 264 from Akithii division $(\mathrm{N}=525)$. Two cross-sectional studies were undertaken, approximately 6 months apart.

The first phase of the study was conducted during the dry season and the second phase after the rainy season. The dry season took place when the food stores were low. October-November is a period when residents are most hungry since it is before the rains came. The rainy season took place when the food stores were normally good in this area since it was after the harvest of the short rainy period. The repeated surveys were not at the same households but households were randomly selected during both phases of the study. Interviews were conducted by trained nutrition graduates from Kenyatta University with mothers/caregivers of children aged 2459 months. 


\section{Data collection}

\section{Socio-economic and demographic questionnaire}

The socio-demographic part of the questionnaire elicited information on the socio-economic status of the household; particularly questions on household assets. The latter have an influence on the economic status of the household which could in turn influence household food security.

\section{Dietary intake and adequacy}

Dietary intake of each child was measured using a repeated 24-hour recall [23] with the mother/care giver of the index child in the household. Several days lapsed between the repeated interviews. Two 24-hour recalls were conducted in the dry season and two in the rainy season. The mother was asked to report all the food and drinks consumed by the subject during the previous 24 hours, starting with the first meal of the day and ending with the foods eaten last before bed time. In order to assist her with recall she was taken through the child's activities of the day. In order to determine food portion sizes the interviewer used life-size photographs of food portions [24]. Standard size household utensils such as spoons, cups and mugs were also used to assist in clarifying the amounts of foods and liquids consumed. After the interviews the dietary data was coded and analyzed using food composition tables [25].

In order to determine the nutrient adequacy of the diet the nutrient adequacy ratio (NAR \%) was calculated for each of 12 nutrients and energy, namely: vitamins A, B6, B12, C, B1, B2, niacin, folate; minerals- calcium, iron, and zinc and protein and energy. NAR\% was calculated as being the $\%$ of the nutrient consumed, divided by the recommended nutrient intake (RNI) using the FAO/ WHO recommended nutrient, energy and protein intakes [26-28]. The FAO/WHO RNIs were used because they are regarded as being more suitable for developing countries mainly due to the fact that they take into consideration the bioavailability of iron and zinc. The RNI = $E A R+2 S D_{\text {EAR }}[26]$. For iron and zinc the category of moderate bioavailability was used in this study. Each child was analyzed within their own age nutrient category when doing the dietary data analysis. This meant that cut-off points for the individual age groups were used. Once the NARs were calculated the mean adequacy ratio (MAR) of the diet was determined by the sum of each NAR divided by the number of nutrients. For both NAR and MAR $100 \%$ is the ideal since it means that the intake is the same as the requirement.

\section{Agricultural biodiversity}

Penafiel et al. [29], described the assessment of local biodiversity as listing the local edible plants and animals included in the diet of the population. The Food and Agriculture Organization (FAO) [30], proposed developing an inventory of food biodiversity available from key informants and interviews or focus group discussions.

In the present study the researchers constructed a questionnaire using guidelines from FAO [30]; for developing indicators for monitoring agricultural biodiversity and also from a previous study undertaken in Kenya [22]. This questionnaire was pretested to improve its validity. In-depth interviews were held with key informants (village elders) and 4 focus group discussions with 8-12 participants were held with those deemed to have knowledge of local foods, to corroborate data obtained by questionnaire.

Agricultural biodiversity was measured by determining the variety of food plants grown, animals reared for food and food items obtained from natural habitats in the past year. A list of all food items grown, all animals reared and hunted, and other food items obtained from natural habitats through gathering or trapping was determined for each household by means of a short questionnaire which asked the participant to list all the food items utilized over the past year (dry and rainy seasons). Food items purchased from markets or towns were not included in the agricultural biodiversity score.

A score of biodiversity was calculated for each household according to which indigenous and cultivated food items were used at any time by the household over a period comprising the past year. The maximum found was 26. Each household's biodiversity score was then correlated with the individual nutrient adequacy ratios from the repeated 24 hour recalls of the child participant in that household.

\section{The Household Food Insecure Access Scale (HFIAS)}

Food security was assessed by means of the HFIAS developed by Coates et al. [31]. The HFIAS is internationally used and is regarded as being a valid instrument for this purpose. This assessment tool is based on the principle that the experience of food insecurity causes predictable reactions and responses that can be captured and quantified through a survey and summarized in a scale. The nine-item scale uses a four-week recall period and was constructed to capture three larger dimensions of household food insecurity: anxiety and uncertainty about household food access: insufficient quality and insufficient food intake and its physical consequences or hunger [31].

The information generated by the HFIAS was used to assess the prevalence of household food insecurity and to detect changes in the household food security situation of the population during the two seasons, namely the dry season and rainy season (after harvest season). Since the study period included both seasons, HFIAS generic questions were adapted and translated to ensure 
that questions were understood in their cultural context. The first phase of the study took place when the food stores were low. October-November is a period when respondents are most hungry since it is before the rains come. The second phase of the study, took place when the food stores were normally good in this area since it was after the harvest of the short rainy period.

The HFIAS was used to determine the prevalence of household food insecurity. The HFIAS is a continuous measure of the degree of food insecurity in the household in the past four weeks (30 days). First, a HFIAS score variable was calculated for each household by summing the codes of each frequency-of-occurrence question. The maximum score for a household is 27 . The higher the score, the more food insecurity (lower access) the household experienced. The lower the score, the less food insecurity a household experienced [31]. In order to report household food insecurity prevalence (HFIAP) [31], the HFIAP indicator was used to categorize households into four levels of household food insecurity: i) food secure $(0-1)$ ii) mildly food insecure, (2-9) iii) moderately food insecure (10-14) and iv) severely food insecure (15+).

\section{Ethics}

The study was approved by the Committee for Human Research, Faculty of Medicine and Health Sciences, Stellenbosch University (ethics reference No. N11/02/037). Each participant was required to sign a consent form after the purpose of the study had been explained to them. Thumb prints were used for participants who could not write. The researcher also obtained permission to conduct the research from the National Commission of Science, Technology and Innovations of Kenya.

\section{Data analysis}

The entry of the raw data was done using Microsoft Access 2003 and exported to MS Excel 2003. Data cleaning was done before the data was transported to the data analysis packages. STATISTICA version 9 (StatSoft Inc. (2009) STATISTICA (data analysis software system) (www.statsoft.com), Statistical Package for Social Sciences (SPSS Version 11.5) were used to analyze the data. Food finder 3, [25], was used to analyze the dietary data that was collected using the 24-hour recall. This is a software product developed by the Medial Research Council of South Africa [25]. Kenyan foods were added to the database from previous studies.

\section{Results}

Forty-one percent of mothers/caretakers were casual laborers, $19.5 \%$ were petty traders, $5.4 \%$ were unemployed, $4.5 \%$ were self-employed and $1.2 \%$ were wage earners (data not shown). The majority (84.6\%) of mothers/care givers had a primary level of education, 5.0\% had some secondary education, $4.4 \%$ had completed secondary education and $5.0 \%$ had no formal education. Ninety-six percent of the respondents owned land which was under food production and all (100\%) had a food or grain store in their homes. All (100\%) the respondents were small scale farmers. The mean acreage of land under food production for both divisions was $1.4 \pm 1.1$. There was a significant difference in the size of farms under food production between Akithii and Uringu. [Akithii $1.5 \pm$ 1.04 hectares, Uringu $1.2 \pm 1.00$ hectares $(\mathrm{p}<0.001)]$. Respondents from Akithii had relatively larger farms under food production compared to those in Uringu. Overall, in both areas participants owned their own homes (99.1\%) (Table 1). Other assets owned by a substantial number of households were sofa sets, vegetable gardens and fruit trees. Significant differences between the two divisions were found in the ownership of radios $(\mathrm{p}=$ $0.019)$, sofa sets $(p=0.002)$, vegetable gardens $(p=0.015)$ and fruit trees $(\mathrm{p}<0.0001)$. More residents of Uringu had vegetable gardens and fruit trees while a greater number

Table 1 Assets owned by families in the two study areas

\begin{tabular}{|c|c|c|c|c|c|c|c|}
\hline \multirow[t]{2}{*}{ Household assets } & \multicolumn{2}{|c|}{ Akithii $N=261$} & \multicolumn{2}{|c|}{ Uringu $N=264$} & \multicolumn{2}{|c|}{ Total for both divisions } & \multirow[t]{2}{*}{ Chi-square $p$-values } \\
\hline & $\mathrm{N}$ & $\%$ & $\mathrm{~N}$ & $\%$ & $\mathrm{~N}$ & $\%$ & \\
\hline Own home & 261 & 99.6 & 258 & 98.5 & 519 & 99.1 & $X=1.829 ; p=0.176$ \\
\hline Television set & 34 & 13 & 39 & 14.9 & 73 & 14.0 & $X=0.421 ; p=0.517$ \\
\hline Radio & 156 & 59.5 & 181 & 69.1 & 337 & 64.3 & $X=5.487 ; p=0.019^{*}$ \\
\hline Vehicle & 2 & 0.8 & 6 & 2.3 & 8 & 1.6 & $X=2.047 ; p=0.153$ \\
\hline Bicycle & 135 & 51.5 & 121 & 8.0 & 256 & 29.8 & $X=0.017 ; p=0.896$ \\
\hline Wheelbarrow & 23 & 8.8 & 25 & 9.5 & 48 & 9.2 & $X=0.100 ; p=0.751$ \\
\hline Sofa set & 134 & 51.1 & 100 & 38.2 & 234 & 44.7 & $X=9.202 ; p=0.002^{* *}$ \\
\hline Cell phone & 194 & 74.0 & 183 & 69.8 & 377 & 71.9 & $X=1.204 ; p=0.272$ \\
\hline Vegetable garden & 75 & 28.6 & 101 & 38.5 & 176 & 33.6 & $X=5.940 ; p=0.015^{*}$ \\
\hline Fruit trees & 81 & 30.9 & 206 & 78.6 & 287 & 54.8 & $X=119.689 ; X=p<0.001^{* * *}$ \\
\hline
\end{tabular}

${ }^{*} p<0.05 ;{ }^{* *} p<0.01 ;{ }^{* * *} p<0.001$. 
Table 2 Macronutrient intakes of 24-59 month old children derived from repeated 24-hour recalls in the dry and rainy seasons of the two areas studied

\begin{tabular}{|c|c|c|c|c|c|c|c|c|c|c|c|c|c|}
\hline \multirow{3}{*}{ Nutrient } & \multicolumn{4}{|c|}{ Dry season } & \multicolumn{4}{|c|}{ Rainy season } & \multicolumn{4}{|c|}{ Both combined } & \multirow{3}{*}{ FAO RNI } \\
\hline & \multicolumn{2}{|c|}{ Akithii $^{\mathrm{a}}$} & \multicolumn{2}{|c|}{ Uring $^{a}$} & \multicolumn{2}{|c|}{ Akithii } & \multicolumn{2}{|l|}{ Uringu } & \multicolumn{2}{|c|}{ Akithii $^{\mathbf{b}}$} & \multicolumn{2}{|c|}{ Uringu $^{b}$} & \\
\hline & Mean & SD & Mean & SD & Mean & SD & Mean & SD & Mean & SD & Mean & SD & \\
\hline Energy-(kJ) & 3392 & 2069 & 3684 & 1599 & $3808^{* * *}$ & 1914 & $4149^{* * *}$ & 1673 & 3599 & 2002 & $3908^{* *}$ & 1650 & $4276-5656$ \\
\hline Carbohydrate (g) & 127 & 67 & 134 & 55 & $149 * * *$ & 74 & $153^{* * *}$ & 60 & 138 & 71 & 143 & 58 & - \\
\hline Added sugar (g) & 5.2 & 15.76 & 6.0 & 14.43 & $7.8^{* *}$ & 14.54 & $12.3^{* *}$ & 24.12 & 6.5 & 15.21 & $9.1^{*}$ & 19.93 & - \\
\hline Total protein (g) & 20.6 & 12.33 & 22.3 & 11.98 & $23.9^{* *}$ & 13.10 & $25.5^{* *}$ & 11.78 & 22.2 & 12.81 & $23.8^{*}$ & 11.98 & $14-22.2$ \\
\hline Animal protein (g) & 1.4 & 3.11 & $2.1^{*}$ & 3.47 & 1.6 & 2.40 & $2.7^{*}$ & 4.35 & 1.5 & 2.78 & $2.4^{* * *}$ & 10.37 & - \\
\hline Vegetable protein (g) & 19.1 & 11.51 & 18.7 & 10.47 & $21.9^{* *}$ & 12.33 & $22.5^{* * *}$ & 9.92 & 20.5 & 11.99 & 20.5 & 10.37 & - \\
\hline Total fat (g) & 17.5 & 22.95 & 21.1 & 17.86 & 15.9 & 15.51 & 22.1 & 18.39 & 16.7 & 19.60 & $21.6^{* * *}$ & 18.10 & - \\
\hline Poly-unsaturated fat (g) & 4.9 & 5.90 & 6.6 & 6.37 & 4.1 & 4.14 & 6.2 & 6.40 & 4.5 & 5.11 & $6.4^{* * *}$ & 6.03 & - \\
\hline Saturated fat (g) & 4.1 & 5.45 & 4.9 & 4.57 & $5.7^{*}$ & 9.36 & $5.7^{*}$ & 5.64 & 4.9 & 7.69 & 5.3 & 5.53 & - \\
\hline Fiber (g) & 13.7 & 7.68 & 15.7 & 7.39 & $16.9^{* * *}$ & 9.83 & $17.8^{* * *}$ & 7.97 & 15.3 & 8.95 & $16.7^{* * *}$ & 7.74 & $19-25$ \\
\hline
\end{tabular}

${ }^{a}$ Significant difference between mean values using t-test: ${ }^{*} \mathrm{p}<0.05 ;{ }^{* *} \mathrm{p}<0.01 ;{ }^{* * *} \mathrm{p}<0.001$ between the dry and rainy seasons; ${ }^{\mathrm{b}}$ between the two areas; $\mathrm{RNI}=$ recommended nutrient intakes.

of residents in Akithii had bicycles, sofa sets and cell phones.

A comparison of the mean nutrient intakes of macronutrients between the two seasons $(1=$ dry season; 2 = after rain) is displayed in Table 2. Significant increases in mean nutrient intakes were found between the two phases in both areas, namely: energy $(\mathrm{p}<0.001)$; carbohydrate $(\mathrm{p}<0.001)$; added sugar $(\mathrm{p}<0.001)$; total protein $(\mathrm{p}<0.01)$; vegetable protein $(\mathrm{p}<0.001)$; saturated fat $(\mathrm{p}<$ $0.05)$; and fiber $(\mathrm{p}<0.001)$. Mean intakes were generally greater in Uringu compared to Akithii. Mean energy and fiber intakes were lower than the RNIs.
A comparison of the mean micronutrient intakes between the two phases was done (Table 3). Mean intakes of calcium, zinc, vitamin A, riboflavin and niacin were below the RNIs. With regard to the two seasons it should be noted that there were significant improvements in certain micronutrients in the rainy season in both areas, namely calcium $(\mathrm{p}<0.05)$; iron $(\mathrm{p}<0.01)$; zinc $(\mathrm{p}<0.0 .05)$ and folate $(\mathrm{p}<0.01)$. However the mean intake of vitamin A decreased in both areas.

The lowest NAR values were found for vitamin B12 and calcium (Table 4). Vitamin B12 values were less than $25 \%$ and calcium less than $40 \%$ of the requirement,

Table 3 Micronutrient intakes of 24-59 month old children derived from repeated 24-hour recalls in the dry and rainy seasons of the two areas studied

\begin{tabular}{|c|c|c|c|c|c|c|c|c|c|c|c|c|c|}
\hline \multirow{3}{*}{ Nutrient } & \multicolumn{4}{|c|}{ Dry season } & \multicolumn{4}{|c|}{ Rainy season } & \multicolumn{4}{|c|}{ Combined seasons } & \multirow{3}{*}{ FAO RNI } \\
\hline & \multicolumn{2}{|c|}{ Akithii } & \multicolumn{2}{|l|}{ Uringu } & \multicolumn{2}{|c|}{ Akithii } & \multicolumn{2}{|l|}{ Uringu } & \multicolumn{2}{|c|}{ Akithii } & \multicolumn{2}{|l|}{ Uringu } & \\
\hline & Mean & SD & Mean & SD & Mean $^{a}$ & SD & Mean $^{a}$ & SD & Mean & SD & Mean'b & SD & \\
\hline Calcium (mg) & 146 & 108 & 196 & 137 & $155^{*}$ & 134 & $200^{*}$ & 154 & 151 & 122 & $199 * * *$ & 145 & $500-600$ \\
\hline Iron (mg) & 4.6 & 2.76 & 5.4 & 2.79 & $5.5^{* *}$ & 3.68 & $6.3^{* *}$ & 3.52 & 5.1 & 3.27 & $5.9^{*}$ & 3.19 & 6.0 \\
\hline Zinc (mg) & 2.6 & 1.51 & 3.1 & 1.81 & $3.1^{*}$ & 1.71 & $3.5^{*}$ & 1.89 & 2.9 & 1.63 & $3.3^{* *}$ & 1.86 & $4.1-6.1$ \\
\hline Vitamin A (ug) & $581^{*}$ & 577 & $587^{*}$ & 532 & 288 & 399 & 398 & 517 & 435 & 517 & $496^{* *}$ & 533 & $400-450$ \\
\hline Vitamin C (mg) & 38 & 38.6 & $62^{*}$ & 51.1 & 34 & 41.3 & 57 & 47.4 & 36 & 40 & $60^{* * *}$ & 49.3 & 30 \\
\hline Folate (ug) & 187 & 227.4 & 213 & 184.3 & $258^{* *}$ & 181.9 & $261^{* *}$ & 150.8 & 222 & 208.8 & 236 & 170 & $160-200$ \\
\hline Thiamin (mg) & 0.5 & 0.56 & 0.6 & 0.46 & 0.6 & 0.36 & 0.6 & 0.30 & 0.6 & 0.47 & 0.6 & 0.38 & $0.5-0.6$ \\
\hline Riboflavin (mg) & 0.3 & 0.57 & 0.3 & 0.48 & 0.3 & 0.27 & 0.3 & 0.22 & 0.3 & 0.45 & $0.3^{*}$ & 0.38 & $0.5-0.6$ \\
\hline Niacin (mg) & 3.3 & 5.31 & 4.6 & 5.37 & 3.2 & 2.79 & 4.2 & 3.35 & 3.2 & 4.24 & $4.4^{* * *}$ & 4.51 & $6-8$ \\
\hline Vitamin 6 (mg) & 0.5 & 0.40 & 0.6 & 0.41 & 0.5 & 0.36 & 0.6 & 0.39 & 0.5 & 0.38 & $0.6^{* * *}$ & 0.41 & $0.5-0.6$ \\
\hline Vitamin B12 (ug) & 0.2 & 0.81 & 0.2 & 0.33 & 0.2 & 0.29 & 0.3 & 0.41 & 0.2 & 0.61 & $0.3^{* * *}$ & 0.37 & $0.9-1.2$ \\
\hline
\end{tabular}

${ }^{\mathrm{a}}$ Significant difference between mean values using t-test: ${ }^{*} \mathrm{p}<0.05 ;{ }^{* *} \mathrm{p}<0.01 ;{ }^{* * *} \mathrm{p}<0.001$ between the dry and rainy seasons; ${ }^{\mathrm{b}}$ between the two areas; $\mathrm{RNI}=$ recommended nutrient intakes. 
Table 4 Nutrient adequacy ratios of nutrients and mean adequacy ratio of the nutrients of 24-59 month old children derived from repeated 24-hour recalls in the dry and rainy seasons

\begin{tabular}{|c|c|c|c|c|c|c|c|c|}
\hline \multirow{4}{*}{ Nutrient } & \multicolumn{4}{|c|}{ Dry season } & \multicolumn{4}{|c|}{ Rainy season } \\
\hline & \multicolumn{2}{|l|}{ Akithii } & \multicolumn{2}{|l|}{ Uringu } & \multicolumn{2}{|l|}{ Akithii } & \multicolumn{2}{|l|}{ Uringu } \\
\hline & Mean & SD & Mean & SD & Mean & SD & Mean & SD \\
\hline & \multicolumn{2}{|l|}{ NAR } & \multicolumn{2}{|l|}{ NAR } & \multicolumn{2}{|l|}{ NAR } & \multicolumn{2}{|l|}{ NAR } \\
\hline Energy & 36.2 & 21.10 & 39.5 & 16.1 & $40.9^{* * *}$ & 20.42 & $44.5^{* * *}$ & 17.48 \\
\hline Protein & 41.5 & 21.62 & 44.4 & 19.77 & $48.7^{* * *}$ & 26.61 & $52.0^{* * *}$ & 24.02 \\
\hline Vitamin A & $66.2^{* * *}$ & 39.83 & $73.5^{* * *}$ & 34.14 & 44.8 & 39.14 & 61.5 & 33.70 \\
\hline Vitamin B6 & 67.1 & 30.72 & 85.8 & 20.23 & 71.0 & 30.25 & 85.5 & 21.36 \\
\hline Vitamin B12 & 15.4 & 26.01 & 21.9 & 26.65 & 18.4 & 23.41 & 25.7 & 28.31 \\
\hline Vitamin C & $66.4^{* *}$ & 38.81 & $89.4^{*}$ & 24.35 & 55.0 & 41.60 & 81.9 & 31.94 \\
\hline Niacin & 43.7 & 25.52 & 60.0 & 26.71 & 46.8 & 28.42 & 57.80 & 25.65 \\
\hline Riboflavin & 45.0 & 26.84 & 54.7 & 23.92 & $50.4^{*}$ & 26.50 & 58.4 & 24.54 \\
\hline Thiamin & 77.7 & 24.25 & 84.0 & 21.43 & 80.7 & 23.93 & 87.4 & 18.73 \\
\hline Folate & 74.4 & 30.96 & 85.0 & 22.08 & $85.4^{* * *}$ & 23.71 & $92.3^{* * *}$ & 17.42 \\
\hline Iron & 67.0 & 29.88 & 77.4 & 23.59 & $72.0^{*}$ & 29.50 & $83.0^{* * *}$ & 20.13 \\
\hline Calcium & 28.1 & 20.73 & 36.8 & 22.25 & 29.2 & 23.60 & 36.5 & 22.93 \\
\hline Zinc & 57.5 & 27.46 & 67.1 & 24.04 & $65.1^{* *}$ & 27.62 & $71.8^{*}$ & 22.66 \\
\hline $\mathrm{MAR}^{\# \#}$ & 55.3 & 23.65 & 66.8 & 17.19 & 56.3 & 23.23 & 67.4 & 17.76 \\
\hline
\end{tabular}

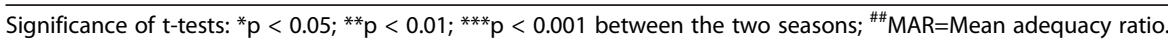

respectively. Energy and protein NARs were all less than $50 \%$ of the RNI. The highest NARs of $70 \%$ and above were found for vitamin B6, C, thiamin, folate and iron. When combining the micronutrients to provide a MAR value, it was found to be $55.3 \%$ for Akithii and $66.8 \%$ for Uringu in the dry season and 56.3 and 67.4 in the rainy season, respectively; representing an improvement which was not significant. Comparison of the means of the two seasons showed significant improvements in energy $(p<0.001)$; protein $(p=0.001)$; folate $(p<0.001$; zinc $(\mathrm{P}<0.01)$; and iron $(\mathrm{p}<0.01)$. Uringu consistently had higher means for all the NARs, which means that the children in Uringu had a higher MAR than those in Akithii, reflecting a diet of better quality.

Table 5 shows that the cereal group was consumed by nearly all children followed by the vitamin A-rich fruits and vegetables. The next group most commonly consumed was the dairy group. Consumption of meat and eggs were very low in both areas. The table further indicates that there is an increase in percentage children

Table 5 Percent of children consuming foods from different food groups in the dry and rainy seasons

\begin{tabular}{|c|c|c|c|c|c|c|c|c|}
\hline \multirow[t]{3}{*}{ Food group } & \multicolumn{2}{|c|}{ Akithii } & \multicolumn{2}{|c|}{ Uringu } & \multicolumn{2}{|c|}{ Akithii } & \multicolumn{2}{|c|}{ Uringu } \\
\hline & \multicolumn{2}{|c|}{ Dry season } & \multicolumn{2}{|c|}{ Dry season } & \multicolumn{2}{|c|}{ Rainy season } & \multicolumn{2}{|c|}{ Rainy season } \\
\hline & $\%$ & SE & $\%$ & SE & $\%$ & SE & $\%$ & SE \\
\hline Cereals, roots and tubers & 98.5 & 1.0 & 96.2 & 3.8 & 98.9 & 0.68 & 98.2 & 0.9 \\
\hline Vitamin A rich fruits \& veg & 74.5 & 4.2 & 91.3 & 2.8 & 59.6 & 0.5 & 78.0 & 0.07 \\
\hline Other fruits \& vegetables & 13.6 & 6.0 & 47.7 & 7.4 & 23.1 & 4.9 & 52.0 & 1.3 \\
\hline Sugars, syrup and sweets & 26.7 & 2.1 & 28.4 & 3.0 & 45.3 & 0.9 & 56.5 & 1.4 \\
\hline Legumes \& nuts & 17.9 & 2.5 & 46.4 & 0.2 & 28.8 & 6.3 & 44.6 & 4.3 \\
\hline Meat, poultry, fish & 1.7 & 0.01 & 2.1 & 0.4 & 0.6 & 0.2 & 2.2 & 1.7 \\
\hline Fats \& oils & 13.8 & 5.3 & 18.9 & 1.9 & 13.7 & 0.1 & 11.7 & 0.3 \\
\hline Dairy products & 50.4 & 2.5 & 79.4 & 4.9 & 61.9 & 2.1 & 78.7 & 0.2 \\
\hline Eggs & 0.4 & 0.003 & 1.1 & 0.2 & 0.7 & 0.2 & 0.9 & 0.01 \\
\hline Beverages* & 0.8 & 0.3 & 0.9 & 0.03 & 1.0 & 0.3 & 1.5 & 0.4 \\
\hline
\end{tabular}

*When doing the 24 hour recalls, black tea or coffee were not included as foods used in calculating nutrient intakes since they do not contain any macro- or micronutrients. However if milk was added to the tea or coffee, the milk portion was added to the dairy group. Hence the beverages referred to in the table are cold drinks. 
Table 6 The household food security mean scores in the two areas studied during the dry and rainy seasons

\begin{tabular}{llll}
\hline & $\begin{array}{l}\text { Akithii } \\
\text { Mean (SD) }\end{array}$ & $\begin{array}{l}\text { Uringu } \\
\text { Mean (SD) }\end{array}$ & $\begin{array}{l}\text { Combined } \\
\text { Mean (SD) }\end{array}$ \\
\hline Dry season & $16.2(7.01)^{* * *}$ & $10.0(6.90)$ & $13.1(6.91)^{* * *}$ \\
Rainy season & $12.5(7.80)$ & $9.3(7.02)$ & $10.9(7.42)$ \\
\hline
\end{tabular}

***The two tailed $\mathrm{p}$ value $<0.001$ (t-test) indicates a significant difference between the means of the dry and rainy seasons. A lower score is indicative of better household food security.

consuming certain groups in the rainy season in both areas. These are non-vitamin A rich fruits and vegetables ( $\mathrm{A}=13.6 \%$ to $23.1 \% ; \mathrm{U}=47.7 \%$ to $52 \%$ ); sugars and sweets $(A=26.7 \%$ to $45.3 \%$; $U=28.4$ to $56.5 \%$; legumes (A only $=17.9 \%$ to $28.8 \%$ ); and dairy (A only $=50.4 \%$ to $61.9 \%$ ). In both areas the percent children consuming vitamin $\mathrm{A}$ rich fruit and vegetables decreased $(\mathrm{A}=74.5$ to $59.6 \%$; $U=91.3 \%$ to $78 \%$ ). The 10 most commonly consumed food items were maize meal, maize with beans, tea, kale, sugar, spinach and potatoes, tomatoes, boiled maize and chapattis in the dry season and tea, maize meal, maize and beans, milk, sugar, onions, mango, rice and beans, tomatoes and potatoes in the rainy season (not shown).

To assess whether the household food security situation was influenced by the change in seasonality, a comparison was done between the two seasons of data collection. Table 6 shows the HFIAS mean scores during the two seasons. For Akithii and both areas combined the scores are significantly higher during the dry season which is indicative of poorer household food security during this season. This is also illustrated in Figures 1 and 2 which show that the prevalence of severe food insecurity decreases during the rainy season. Figure 3 shows that households that were food secure were likely to have children with a higher MAR $(p=0.002)$. Households that were food secure and mildly food insecure had a higher MAR than those that were moderately and severely food insecure.

The total number of different food items (agricultural biodiversity) in the two areas over the past year as reported by participants and focus groups are presented in Table 7. They include cultivated food items and those obtained from the natural habitat. The majority of items were cultivated $(n=23)$; with only three obtained from the wild. The latter being wild berries, Amaranthus blitum and antelope (deer).

Correlations between agricultural biodiversity scores of participants and their NARs are shown in Table 8. A significant relationship was found to exist between the agricultural biodiversity score with all the nutrients investigated in the study with the exception of energy. Since the correlations are positive it is noted that increased NAR (dietary adequacy) of the child is associated with an increased agricultural biodiversity score of the household.

A significant relationship was also found to exist between agricultural biodiversity and household food security (HFIAS) (Spearman, $\mathrm{p}=0.02$ ) (Figure 4). As the agricultural biodiversity score increased, the HFIAS score decreased, showing that an increase in agricultural biodiversity improved household food security.

\section{Discussion}

In summary, results for dietary adequacy showed that children had poor intakes of energy, protein, fiber and numerous micronutrients. The low energy intake helps to explain the high degree of chronic malnutrition found in these children with stunting at $31.9-34.7 \%$ in Akithii and $26.23-28.2 \%$ in Uringu [32]. It is interesting to note

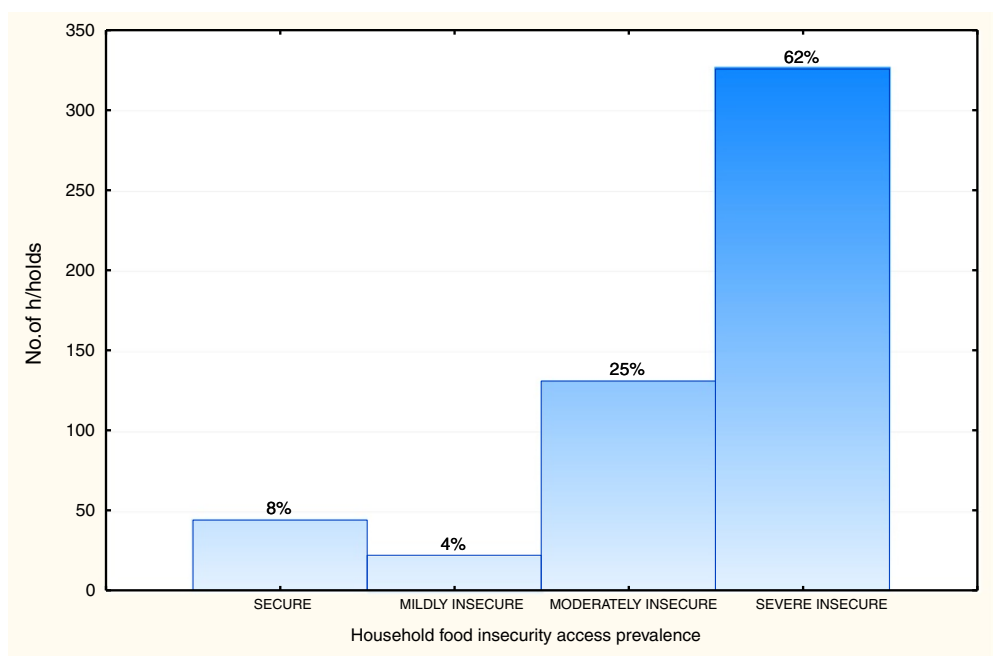

Figure 1 Household food insecurity access prevalence categories for the two divisions in the dry season. 


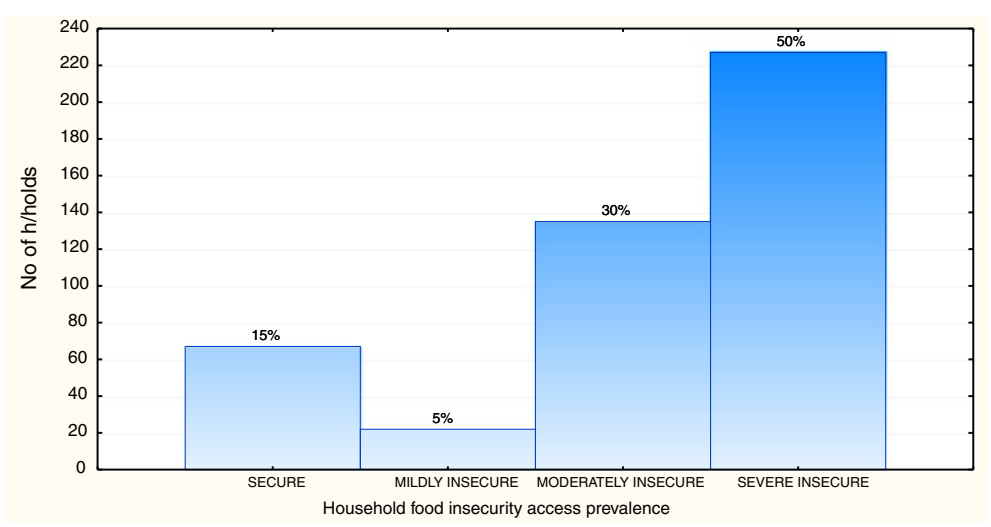

Figure 2 Household food insecurity access prevalence categories for the two divisions in the rainy season.

that the children in Uringu were generally better off than those in Akithii in terms of dietary adequacy, food security and agricultural biodiversity. However, one of the most important outcomes of the study were the significant improvements in dietary adequacy and in household food security during the rainy season. In both areas there were significant increases in energy, carbohydrate, protein, saturated fat, sugar and fibre. Many micronutrients, including calcium, zinc, iron and folate also increased significantly in both areas in the rainy season. Vitamin A was the only micronutrient not to do so and this was likely due to the finding that the main vitamin A source (spinach and kale) was consumed in the dry season. Increases in the percentage children consuming certain food groups also showed an upward trend in non-vitamin A rich fruit and vegetables, sugar, legumes, and dairy products, in the rainy season.

Additionally, household food security as measured by the HFIAS also improved significantly during the rainy season, further emphasizing the importance of seasonal effects on households. These findings are similar to those of a study conducted in Mozambique that found that change in seasonality affected household food security as measured by the HFIAS [33]. Researchers who undertake dietary surveys in countries like Kenya need to be aware of the importance of including data from different seasons.

Kenya has been described as a country rich in agricultural biodiversity with an estimated 35,000 known species of animals, plants and micro-organisms [34]. The country's agricultural biodiversity is, however, under serious threat due to among others increasing deforestation, climate change, pollution and soil degradation [35]. The level of agricultural biodiversity $(n=26)$ and the mean scores (6.6 and 7.2, respectively) in the Eastern part of Kenya, the area of study, was found to be low and far less than the number described in an earlier study conducted in western Kenya which found 41 different species of food cultivated, animals reared and those foods from the natural habitat [22]. Our methodology was similar to the one used in this earlier study. However despite the lower figure, the present study showed a significant

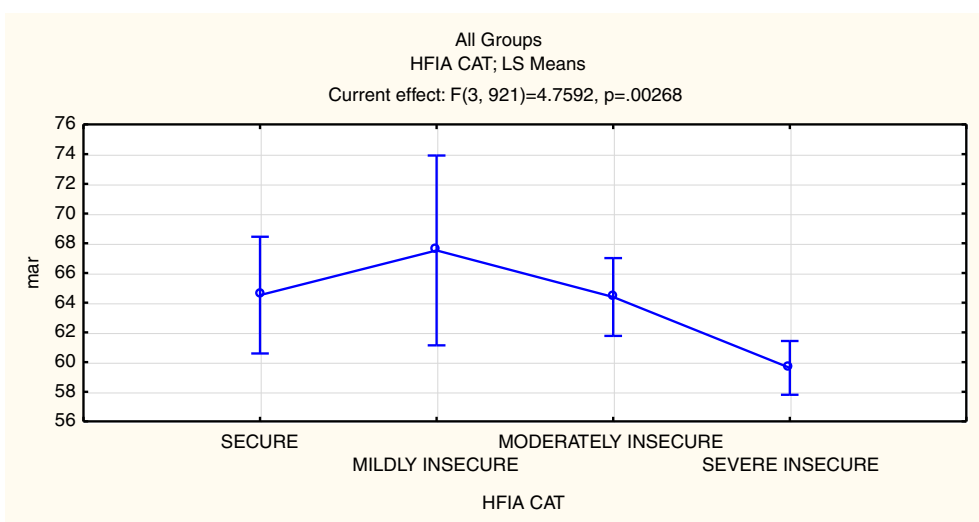

Figure 3 Comparing Household Food Insecurity Access categories (HFIACAT) with theMicronutrient Adequacy Ratio (MAR). 
Table 7 Total number of different food items (agricultural biodiversity) in the two areas over the past year as reported by participants* and focus groups

\begin{tabular}{lll}
\hline Categories & Types of food items & Natural habitat \\
\cline { 2 - 3 } Animals & Domesticated/cultivated & Antelopes \\
Cereals, pulses and roots & Goats, pigs, chicken, rabbit, sheep, ducks, cows & None \\
& arrow roots & \\
Nuts & Ground nuts, macadamia nuts & None \\
Fruits & Paw paws, avocadoes, bananas, oranges, mangoes & Wild berries \\
Vegetables & Kales and tomatoes & Amaranth sp Amaranthus blitum (terere) \\
Total biodiversity & 23 & 3 \\
\hline
\end{tabular}

*Mean agricultural biodiversity scores was 6.6 (SD 2.44) in Akhitii and 7.2 (SD 4.19) in Uringu.

positive relationship between agricultural biodiversity and nutrient adequacy ratios (NARs) implying that as one increased so did the other.

A study by Frison [36] indicated that, in Kenya, rice, maize and wheat contribute about $60 \%$ of calories and proteins from plants. The magnitude of agricultural effort applied to the three principal crops has led to a decline in the production and consumption of more diverse grains. This concurs with the findings of the present study which revealed that the production of cereals such as indigenous millet and finger millet has declined and the number of foods which can be obtained from the natural habitat have been significantly reduced. This further corresponds with a study by John, [10] which indicated that cultivation of traditional foods like: millet, sorghum, cassava, sweet potatoes, traditional vegetables and indigenous wild fruits are now associated with being poor. This association results in changes in agricultural practices, which lead to disruption of dietary patterns and loss of dietary diversity.

Table 8 Correlations between agricultural biodiversity score and nutrient adequacy ratios

\begin{tabular}{|c|c|c|c|}
\hline \multicolumn{4}{|l|}{ Spearman rank order correlations } \\
\hline Variables & Spearman - R & $t(N-2)$ & p-value \\
\hline Biodiversity score \& NAR Energy & 0.085 & 1.905 & 0.057 \\
\hline Biodiversity score \& NAR Protein & 0.092 & 2.074 & $0.038^{*}$ \\
\hline Biodiversity score \& NAR Iron & 0.152 & 3.442 & $0.001^{* * *}$ \\
\hline Biodiversity score \& NAR Zinc & 0.130 & 2.921 & $0.003^{* *}$ \\
\hline Biodiversity score \& NAR Vit B12 & 0.118 & 2.663 & $0.007^{* *}$ \\
\hline $\begin{array}{l}\text { Biodiversity score \& NAR } \\
\text { Vitamin B6 }\end{array}$ & 0.193 & 4.381 & $p<0.001^{* * *}$ \\
\hline Biodiversity score \& NAR Vitamin C & 0.176 & 4.003 & $p<0.001^{* * *}$ \\
\hline Biodiversity score \& NAR Folate & 0.091 & 2.054 & $0.040^{*}$ \\
\hline Biodiversity score \& NAR Riboflavin & 0.184 & 4.172 & $p<0.001^{* * *}$ \\
\hline Biodiversity score \& MAR & 0.194 & 4.405 & $p<0.001^{* * *}$ \\
\hline
\end{tabular}

$\mathrm{NAR}=$ nutrient adequacy ratio; $\mathrm{MAR}=$ mean adequacy ratio; Correlations are significant at ${ }^{*} \mathrm{p}<0.05 ;{ }^{* *} \mathrm{p}<0.01 ;{ }^{* * *} \mathrm{p}<0.001$.
The 10 most common food items noted in this study did not include any indigenous foods mentioned above and comprised largely of maize, rice, potatoes and wheat as staple foods.

The relationship between agricultural biodiversity and dietary adequacy (in terms of NARs) was explored in order to quantify the relationship between dietary adequacy and agricultural biodiversity. Highly significant positive correlations were found between agricultural biodiversity and NARs of calcium, iron, zinc, vitamin A, B6, $\mathrm{C}$, folate, riboflavin, protein and energy, indicating the very strong relationship between dietary adequacy and biodiversity. These findings are in agreement with those of other studies which showed a strong relationship between these variables $[37,38]$. The significance of this finding is emphasized by realizing the importance of maintaining or improving biodiversity in populations which are dependent on the land for food [38-40].

Recognition of the value of maintaining and using agricultural biodiversity is not new [38-40]. A significant relationship was found to exist between agricultural biodiversity and food security in this study. As the agricultural biodiversity score increased, the HFIAS score decreased showing that an increase in agricultural biodiversity improved household food security (access). There is limited evidence in SSA of studies linking agricultural biodiversity with household food security and nutritional status. This study showed a significant relationship between agricultural biodiversity and household food security concurring with the recommendation by Frison [11] that it is crucial to study the role of biodiversity as a factor which impacts on household food security. Kenya plans to reduce food insecurity by $30 \%$ by 2015 [41]. Maintaining and improving agricultural biodiversity should therefore form part of the interventions to enable the achievement of this target, especially in rural areas.

To assess whether household food security was influenced by the change in seasonality, a comparison was done between the dry season and the rainy seasons. There were significant differences between results of the 


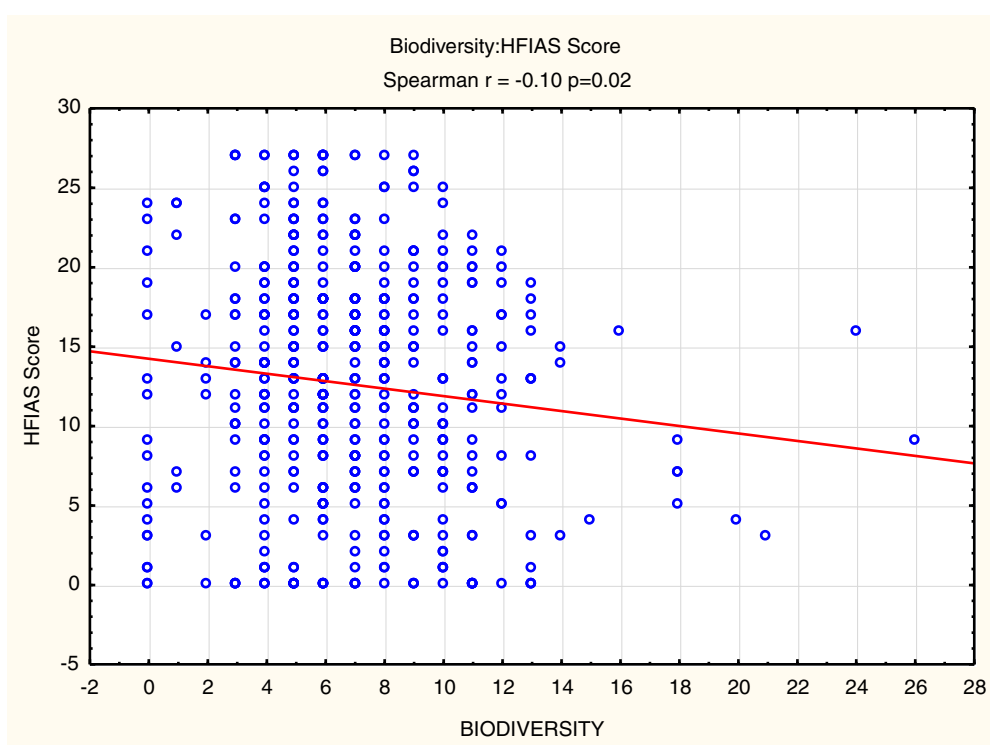

Figure 4 A correlation between the HFIAS score with household agricultural biodiversity scores.

two seasons; with the dry season showing relatively higher levels of food insecurity compared to the rainy season.

Certain limitations of the study need to be noted. Firstly, the two areas studied were not as similar regarding their agricultural and physical resources despite the fact that they were fairly close in physical proximity. Secondly, when evaluating agricultural biodiversity we only examined food items which were cultivated or obtained from the wild. We did not determine the extent to which foods were purchased from stores and markets.

\section{Conclusion}

The dietary intakes of macronutrients and micronutrients were low in this study with most of the preschool children not meeting the recommended nutrient intakes. The following important significant relationships were found in this study: between agricultural biodiversity and dietary adequacy; between agricultural biodiversity and household food security and between dietary adequacy and household food security. Furthermore, the effect of seasonality on household food security and dietary intake of the children was illustrated.

\section{Competing interests}

The authors declare that they have no competing interests.

\section{Authors' contributions}

All the authors contributed to the conception of the study, proposal, fieldwork, and writing up of the final report and article. All authors read and approved the final manuscript.

\section{Acknowledgements}

The authors wish to thank the participants as well as the nutrition graduates who conducted the field work. The South African National Research
Foundation and the National Commission of Science and Technology Kenya are gratefully acknowledged for funding this study.

\section{Author details}

${ }^{1}$ Kenya Technical Teachers College, Nairobi, Kenya. ${ }^{2}$ Division of Human Nutrition, Department of Human Biology, University of Cape Town, Anzio Road, Cape Town, South Africa. ${ }^{3}$ Department of Food, Nutrition and Dietetics, Kenyatta University, Nairobi, Kenya. ${ }^{4}$ Division of Human Nutrition, Stellenbosch University, Cape Town, South Africa. ${ }^{5}$ Division of Human Nutrition, Department of Human Biology, Faculty of Health Sciences, UCT Medical campus, Anzio Road, Anatomy Building, Floor 2, Room 2.04, Observatory 7925 Cape Town, South Africa.

Received: 23 October 2014 Accepted: 20 April 2015

Published online: 25 April 2015

\section{References}

1. Food and Nutrition Technical Assistance (FANTA). Potential uses of food aid to support HIV/AIDS mitigation activities in Sub-Saharan Africa. Washington: Academy of Educational Development; 2000.

2. Food and Agriculture Organization (FAO). Food security committee report. Rome: Food and Agriculture Organization of the United Nations; 2006.

3. Central Bureau of Statistics. Ministry of Planning and National Development of Kenya. Economic Survey. Nairobi: Government Press; 2007.

4. Central Bureau of Statistics, Ministry of Planning and National Development of Kenya. Economic Survey. Nairobi: Government Press; 2008.

5. Government of Kenya (GOK). Kenya food security outlook update: (http://www.fews.net); Accessed 04/05/2009.

6. Government of Kenya (GOK). Kenya food security outlook update: (http://www.fews.net). Accessed 06/07/2011.

7. Demographic and Health (DHS Program). Quick Stats: Kenya. http://dhsprogram.com/Where-We-Work/Country-Main.cfm?ctry_id= $20 \& c=K e n y a \& C o u n t r y=K e n y a \& c n=\& r=1$; (Accessed 9 October 2014).

8. Cromwell E, Cooper D, Mulvany P. Agricultural biodiversity and livelihoods. Institute of Environment and Development: Issues and entry points for development agencies. London; 2001.

9. Pillay D. The conservation of genetic resources within indigenous (underutilized) vegetable plant species in South Africa: Swedish Agricultural University (SLU) and Swedish Biodiversity Centre. (CBM); 2003.

10. John T. Dietary diversity, global change and human health. Montreal, Canada: Proceedings of the Symposium Managing Biodiversity in Agricultural Ecosystems; 2001. 
11. Frison E, Smith IF, Johns T, Cherfas J, Eyzaguirre P. Using biodiversity for food, dietary diversity, better nutrition and health. S Afr J Clin Nutr. 2005;18:112-4

12. Arimond $M$, Torheim D, Wiesmann $M$, Joseph $M$, Carriquiry A. Dietary diversity as a measure of women's diet quality in resource-poor areas: Results from rural Bangladesh site. Washington, DC: Food and Nutrition Technical Assistance (FANTA)and Project/Academy for Educational Development (AED); 2008.

13. Ruel MT. Is dietary diversity an indicator of food security or dietary quality? A review of measurement issues and research needs. Food Nutr Bull. 2002;24:231-2.

14. Victora CG, Adair L, Fall C, Pedro C, Hallal PC, Martorell R, et al. Maternal and child undernutrition: consequences for adult health and human capital. Lancet. 2008;371:340-57.

15. Pelletier DL, Frongillo Jr EA. Changes in child survival are strongly associated with changes in malnutrition in developing countries. Washington DC: FANTA. Academy Educational Development; 2002.

16. Ogle MM, Hung PH, Tuyet HT. Significance of wild vegetables in micronutrient intakes of women in Vietnam: An analysis of food variety. Asia Pacific J Clin Nutr. 2001;10:21-30.

17. Torheim LE, Barikmo I, Parr CL, Hatloy A, Ouattara F, Oshaug A. Validation of food variety as an indicator of diet quality assessed with a food frequency questionnaire for Western Mali. Euro J Clin Nutr. 2003;57:1283-91.

18. Steyn NP, Nel JH, Nantel G, Kennedy G, Labadarios D. Food variety and dietary diversity scores in children: are they good indicators of dietary adequacy? Public Health Nutr. 2006;9(5):644-50.

19. Kennedy GL, Pedro MR, Seghieri C, Nantel G, Brouwer I. Dietary diversity score is a useful indicator of micronutrient intake in non-breast-feeding Filipino children. J Nutr. 2007;137:472-7.

20. Daniels MC, Adair LS, Popkin BM, Truong YK. Dietary diversity scores can be improved through the use of portion requirements: an analysis in young Filipino children. Eur J Clin Nutr. 2009;63:199-208.

21. Moursi MM, Arimond M, Dewey KG, Serge T, Ruel MT, Delpeuch F. Dietary diversity is a good predictor of the micronutrient density of the diet of 6 to 23 month-old children in Madagascar. J Nutr. 2008;138:2448-53.

22. Ekesa BN, Walingo MK, Onyango MO. Role of Agricultural Biodiversity on Dietary Intake and Nutritional Status of Preschool children in Matungu Division, Western Kenya. Afr J Food Sci. 2008;2:026-32.

23. Steyn NP, Labadarios D. Dietary intake:24 hour recall method. In: Labadarios D, editor. The National Food Consumption Survey. Pretoria: Department of Health; 2000.

24. Steyn NP, Senekal M. A guide for the use of the dietary assessment and education kit (DAEK). Cape Town: MRC; 2005.

25. South African Medical Research Council. Food Composition Tables (Food finder software). Cape Town: Nutrition Interventions Unit, South African Medial Research Council; 2001.

26. FAO/WHO. Human vitamin and mineral requirements. Report of a Joint FAO/WHO Expert Consultation. Rome: FAO; 2002.

27. FAO. Human energy requirements: a manual for planners and nutritionists. Oxford: Oxford University Press; 1990.

28. WHO. Energy and protein requirements. Report of a joint expert consultation. Geneva: WHO; 1985

29. Penafiel D, Lachat C, Espinel R, Van Damme P, Kolsteren P. A systematic review on the contributions of edible plant and animal biodiversity to human diets. Ecohealth. 2011:8(3):1-19.

30. Food and Agricultural Organization (FAO). Expert consultation on nutrition indicators for biodiversity 1. Food composition. Rome: FAO; 2008.

31. Coates J, Swindale A, Bilinsky P. Household Food Insecurity Access Scale (HFIAS) for Measurement of Household Food Access: Indicator Guide (v3). Washington, DC: Food and Nutrition Technical Assistance II Project (FANTA-II); 2007

32. M'Kaibi FK, Steyn NP, Ochola SA, Du Plessis L. The role of agricultural biodiversity, dietary diversity, and household food security in households with and without children with stunted growth in rural Kenya. Stellenbosch University, Faculty of Medicine and Health sciences: PhD Thesis; 2014.

33. Food and Agriculture Organization (FAO). Report on use of the Household Food Insecurity Access Scale and Household Dietary Diversity Score in two survey rounds in Manica and Sofala Provinces, Mozambique, 2006-2007: FAO food security project GCP/MOZ/079/BEL. Available online: www.foodsec.org/tr/nut/moz_diet.pdf
34. Government of Kenya (GOK). Agriculture. Natural resource aspects of sustainable development in Kenya. Nairobi: Government Printers; 2001.

35. Food and Agriculture Organization (FAO). Rural women and food security. Current situation and perspectives. Rome: FAO; 2008.

36. Frison E. Dietary Diversity. A Challenge linking human health with plant genetic resources. IPGRI Nutrition Strategy: 2004

37. Burchi F, Fanzo J, Frison E. The role of food and nutrition system approaches in tackling hidden hunger. Int J Environ Res Public Health. 2011;8:358-73. doi:10.3390/ijerph8020358.

38. International B. Improving nutrition with agricultural biodiversity: A manual on implementing food systems field projects to assess and improve dietary diversity, and nutrition and health outcomes. Rome: Biodiversity International; 2011.

39. Brush SB. In situ conservation of landraces in centers of crop diversity. Crop Sci. 1995:35:346-54.

40. Altieri MA, Merrick LC. In situ conservation of crop genetic resources through maintenance of traditional farming systems. Econ Bot. 1987;41:86-96.

41. Jackson L, Hodgkin T. Utilizing and conserving agro-biodiversity in agricultural landscapes. J Nutr. 2006;136:656-63.

\section{Submit your next manuscript to BioMed Central and take full advantage of:}

- Convenient online submission

- Thorough peer review

- No space constraints or color figure charges

- Immediate publication on acceptance

- Inclusion in PubMed, CAS, Scopus and Google Scholar

- Research which is freely available for redistribution 